\title{
Strategies for Prevention and Control of Water Pollution in Villagers' Livestock and Poultry Breeding Industry under the Rural Revitalization Strategy
}

\author{
Dexiang Deng ${ }^{1,2}$, Yan $\mathrm{Wen}^{2}$, and Xi Zhou ${ }^{1,2, *}$ \\ ${ }^{1}$ Xi' an Jiaotong University, School of Human Settlements and Civil Engineering, 710049 No.28 \\ Xianning west road, China \\ ${ }^{2}$ Chongqing University of Posts and Telecommunications, College of Media and Arts, 400065 No.2 \\ Chongwen Road, China
}

\begin{abstract}
The diversified development of villagers' livestock and poultry breeding models according to local conditions is one of the important paths for rural revitalization. Design different operation modes of livestock and poultry breeding and corresponding prevention and control of water pollution measures, establish a coordinated mechanism for villagers' breeding and its water pollution prevention, and develop strategies for villagers' breeding prevention and control of water pollution such as setting up harmless treatment station of dead livestock and poultry in order to achieve the goal of win-win cooperation between villagers' interests, people's needs and rural ecological environment.
\end{abstract}

Key words. Diverse breeding models, Prevention and control of water pollution, Rural revitalization

In a self-sufficient agricultural society, villagers raise livestock and poultry only for their own survival. In the industrial society and the expansion of cities, the demand of urban residents for livestock and poultry is growing. Villagers breeding livestock and poultry must not only supply their own family needs, but also supplement the urban market. Under the dual stimulus of market demand and improvement of their own economic income, some villagers have switched to mainly engaged in livestock and poultry farming. The scale of the villager's livestock and poultry farming has continued to grow, and its proportion in the rural industry has increased. At present, the ever-increasing livestock and poultry farming of villagers has caused significant pressure on the environment and caused certain difficulties for government supervision. It is also impossible to centrally deal with water pollution in the livestock and poultry farming industry. As the villagers have a weaker awareness of environmental protection, when feeding livestock and poultry, they abuse feeds with higher hormones and antibiotics, and unabsorbed hormones and antibiotics are discharged randomly with the excrement of livestock and poultry. Some of

*Corresponding author: 342862686@qqq.com 
the harmful substances in the excrement penetrate the land, Pollution of groundwater and drinking water sources, damage the health of villagers; Part of it is brought into the river with the loss of rainwater, pollutes the surface water, disrupts the balance of the water body, causes the death of aquatic organisms, and also pollutes the surface soil passing by; Villagers mostly use water to clean up livestock and poultry farms, and sewage is directly discharged without treatment, which seriously affects the surrounding environment and ecology.

The national strategy for rural rejuvenation in 2017 proposed that the number of livestock and poultry farming, one of the important paths for rural rejuvenation, increased, but the rural sewage treatment infrastructure was scarcely available. Villagers continue the traditional breeding methods and natural sewage discharge methods. Natural degradation is far from being able to deal with the villagers 'increasing sewage discharge. The situation of many rural water pollution, soil pollution and ecological environment is increasing. If the size of the livestock and poultry breeding industry is restricted, the economic income of the villagers will be reduced, and the supply of meat products will be in short supply, and the price of meat products will soar, affecting the economic market order. In the same year, in order to protect the ecological environment, the government introduced stricter environmental protection laws to restrict retailers raising pigs. Some villagers were forced to abandon the pig breeding industry. The supply and demand of pork was unbalanced. The price of pork kept rising and it quickly affected the market economic order Show up.

As for how to develop the livestock and poultry farming industry of the villagers, prosper the market economy, promote the income of the villagers to become rich, expand the path of rural rejuvenation, and achieve a win-win cooperation between villagers' interests, people's needs and rural ecological environment, it is necessary to develop diversified livestock and poultry breeding mode for the villagers, and the key point is the prevention and control of water pollution in the livestock and poultry breeding industry of villagers.

\section{Strategies for prevention and control of water pollution of diversified livestock and poultry breeding mode}

The villagers are the masters of the village, and the main body of rural revitalization is the villagers. The government should guide the villagers to develop a diversified livestock and poultry model to develop the rural economy, stimulate the sense of democracy in the village, and highlight the main position of the villagers' autonomy in the rural environment. In the following, according to different breeding modes, combining different factors such as the climate, population density, and land area of the villages, different prevention and control of water pollution strategies are designed.

\subsection{Villagers' livestock and poultry breeding park mode and its strategies for prevention and control of water pollution}

For the villages with a large number of livestock and poultry breeding households, standardized villager breeding parks can be developed to form small-scale villager breeding industrial parks that integrate livestock, poultry breeding, slaughtering and processing. The breeding park refers to the breeding park which is organized and constructed by the villagers spontaneously, in addition to the national livestock and poultry breeding park and industrial livestock and poultry breeding park. There are two breeding operation modes in the breeding park, one is that the villagers jointly hire professionals to breed and share 
dividends in proportion; the other is that the villagers enter the breeding park on their own, and carry out breeding or engage in the business of each chain of the breeding park.

\subsubsection{Strategies for prevention of water pollution}

The livestock and poultry breeding zone is divided into breeding staff living areas, livestock and poultry breeding areas, slaughtering areas, meat processing areas and sewage treatment areas. The adoption of zoning and grading water mode, and the usage of terrain height difference design or zonal height difference design so as to form the grading water drop can let the upper water naturally flow to the lower water level for reuse. The living area of the breeding personnel is at the highest level, and the slaughterhouse and meat processing factory are down, and the livestock and poultry breeding area is down, and the lowest is the sewage treatment area.

\subsubsection{Strategies for control of water pollution}

Sewage generated by domestic water such as washing hands and washing dishes and collected rainwater are classified as first-level sewage, without treatment, and sent directly to the collection area through the first-level sewage through pipes. The primary sewage can be used for toilet flushing water, living area, slaughtering area and meat processing area after simple sedimentation treatment.

Slaughtering sewage and meat products in slaughterhouses are processed into low-level sewage and ground-contaminated water, which are classified as secondary sewage and disinfected for cleaning livestock and poultry farms.

High-concentration and highly polluted sewage from human and animal manure, cleaning of livestock and poultry pens, slaughtering and meat processing are classified as tertiary sewage which is directly sent to the sewage treatment area for special treatment. Sewage treatment requires the introduction of urban sewage treatment systems and meets urban sewage treatment standards. Sewage that meets the standards can be recycled or discharged.

\subsection{Villagers' livestock and poultry breeding farm mode and its strategies for prevention and control of water pollution}

More livestock farms can be deployed in rural areas with fewer livestock and poultry farmers and villages with scattered farming of livestock and poultry. The farm is only used for the breeding of livestock and poultry, and the livestock and poultry will be transported to special slaughterhouses and processing plants. The farm is divided into two operation modes: the first is that the villagers jointly raise livestock and poultry and distribute them in proportion; the second is that the villagers independently raise livestock in their own distributive places.

\subsubsection{Strategies for prevention of water pollution}

The scale of individual farms should be controlled to facilitate villagers' nearby breeding, agricultural production by surrounding villagers, and ecologically degradable sewage. The scale of individual livestock and poultry farms should be controlled to facilitate the villagers' nearby breeding, the agricultural production of surrounding villagers, 
and the ecological natural degradation of sewage. Sewage prevention in livestock and poultry farms should be controlled from the source. The use of clean drinking fountains can reduce the concentration of sewage produced by livestock and poultry. Fence flushing methods can reduce the generation of sewage. Through reasonable planning and management of poultry breeding scale, reduce water pollutants.

\subsubsection{Strategies for control of water pollution}

Use "dry manure" and other technologies to separate manure from wastewater. Use wastewater separation equipment to separate sewage and livestock and poultry urine. After harmless treatment of stool and urine, they are used as organic fertilizer for agricultural production. Livestock and poultry farms are equipped with miniature sewage treatment stations, and the separated sewage is sent to the miniature sewage treatment stations, which are discharged after treatment.

Or set up a biogas digester nearby the livestock and poultry farm, sewage is discharged into the biogas digester to produce biogas, and the obtained biogas is used for heat, lighting or power generation of the farm for recycling. Regularly clean up the biogas digester residues and wastewater, and use them as organic fertilizer for agricultural production.

\subsection{Livestock and poultry breeding mode based on the family and its strategies for prevention and control of water pollution}

For villagers who are unwilling to participate in breeding parks and farms, and have a small number of livestock and poultry breeding, as well as special retail households with inconvenient transportation and closed information, they can follow the family-based livestock and poultry breeding model.

\subsubsection{Strategies for prevention of water pollution}

The livestock and poultry breeding model based on the family can be divided into two breeding methods: free-range breeding and captive breeding. This breeding model should establish a complete system of application and approval procedures.

The number of domestic free-range livestock and poultry must be limited to the bearing capacity of surrounding natural environment that can naturally degrade animal manure.

For domestic captive livestock and poultry, the government organizes professionals to teach villagers new captive technologies, encourages villagers to use new captive technologies for breeding, supports villagers to carry out ecological and organic feeding, and reduces livestock and poultry manure and harmful substances.

\subsubsection{Strategies for control of water pollution}

Manure from free-range livestock is degraded naturally.

Livestock and poultry in captivity degrade their manure as much as possible through the fertilizer of crops, and build an earthworm ecological filter under the topography of the manure tank to treat excess manure and sewage. The earthworm ecological filter should also be treated to prevent leakage and the sewage from polluting the groundwater. "Earthworm ecological filter is a new technology for treating domestic sewage by using an artificial ecosystem composed of microorganisms, earthworms and substrates." ${ }^{[1]}$ This technology has a decomposing effect on sewage, and the activities of earthworms are not 
easy to cause blockage of the filter and improve sanitary conditions. Filters are low in cost and easy to manage, providing convenience to villagers.

\section{Reduce water pollution of livestock and poultry manure}

\subsection{Improved breeding methods}

One of the biggest sources of water pollution in the livestock and poultry industry is manure, and the degree of harm caused by the manure depends on the feed the livestock and poultry consume. Professional breeders should regularly train villagers, teach them how to select livestock and poultry feed on the market, and teach villagers how to make scientific feed mixes so that villagers can improve traditional breeding methods.

\subsection{Improve breeding technology}

Water flushing livestock and poultry sheds is convenient and fast, but mixing livestock and poultry manure with sewage makes it difficult to treat sewage, and manure mixed with water cannot be used as agricultural organic fertilizer. Encouraging livestock and poultry farms to use the "dry manure" process technology, first cleaning the manure in the breeding shed and then cleaning the breeding shed can reduce the amount of sewage.

\section{Village community set up harmless treatment station for sick and dead livestock and poultry}

The villagers encountered the death of livestock and poultry, and chose to discard them directly in the land. Viruses and rot bacteria were harmful to their health, and they also polluted the surface environment and groundwater. In response to this problem, the government has constructed corresponding harmless treatment station of dead livestock and poultry according to the situation of the village community. The veterinarians are station staff who are responsible for preventing the epidemic and assisting villagers in the sanitization of dead livestock and poultry. The sick and dead livestock and poultry will be transported to the site by the villagers. The staff will guide and assist the villagers, or work with the villagers to collectively smash the dead and dead livestock and poultry, and then sterilize them with high temperature and high pressure. Finally, they put the livestock and poultry residues into biogas tank for fermentation to produce methane, or use livestock and poultry residues as crop fertilizer.

\section{Establish a water pollution early warning mechanism for villagers' livestock and poultry breeding industry}

Relying on Internet technology, the government has established a remote monitoring and early warning mechanism for water pollution in the livestock and poultry farming industry of villagers, and monitors the sewage treatment and environmental pollution in each breeding park and farm in real time. According to the level of water pollution in China, the four levels of blue, yellow, orange and red should be given early warning with corresponding prevention and control. 


\section{Strengthen publicity and education to cultivate villagers' environmental awareness}

The traditional way of raising livestock and poultry by villagers has been going on for thousands of years, and villagers have no awareness of water pollution brought by livestock and poultry farming. Publicity and education of villagers' environmental awareness should be carried out regularly to understand the harm of livestock and poultry breeding pollution, sort out the concepts of livestock and poultry breeding and pollution prevention, popularize new breeding technologies and change breeding methods.

\section{Conclusion}

Under the strategy of rural revitalization, the slogan of "green water and green mountains are golden mountains and silver mountains" is deeply rooted in the hearts of the people. Rural Revitalization and rural industrial development cannot be at the expense of rural ecological environment, and the development of villagers' livestock and poultry breeding industry cannot be at the expense of environmental pollution. Rural environmental prevention and control should start with the prevention and control of villagers' livestock and poultry breeding water pollution.

\section{References}

1. Y. Liwei, Xi'an University of Architecture and Technology (2011)

2. L. Jianhua, Zhejiang University (2004)

3. H. Qinlou, H. Xiusheng, C. Zhongxuan, Z. Zhenmei, F. Deqing, Anhui Agricultural Science Bulletin, 17, 21-22 (2011)

4. Q. Youjun, Husbandry and Veterinary Medicine, 9 (2019)

5. L. Xiaoyuan, Gansu Animal Husbandry and Veterinary, 5 (2017)

6. Y. Chenyang, L.Liang, Journal of North China University of Water Resources and Electric Power(Natural Science Edition), 5 (2019)

7. J. Yong, China Plant Engineering, 10 (2019)

8. Y. Kaijun, Technology Wind, 34 (2019)

9. Z. Yan, Construction Materials \& Decoration, 35 (2019)

10. C. Jing, Construction Materials \& Decoration, 12 (2019)

This achievement is the result of the 2018 Chongqing Graduate Science and Technology Innovation Project: Theoretical Research and Innovation Practice of Design Poverty Alleviation under the Challenge of Poverty Alleviation (Project No.: cys18261)

This achievement is the result of the 2018 Chongqing Graduate Science and Technology Innovation Project: Research and Practice on the Transformation of Gelao Art and Culture's Rural Revitalization Momentum (Project No.: cys19258) 